\title{
SARCOMA DE KAPOSI EM PACIENTE SUBMETIDO A TRANSPLANTE DE FÍGADO - RELATO DE CASO
}

\author{
Kaposi's Visceral Sarcoma in liver transplant recipient - a case report \\ Ilka de Fátima Santana Ferreira Boin ${ }^{1,2}$, Ana Maria Sampaio ${ }^{1,3}$, Marília Iracema Leonardi1,2, \\ Andréa Mendonça Gusmão Cunha ${ }^{6}$, Jazon Romilson de Souza Almeida 2,4 , Raquel Bello Stucchi ${ }^{2,4}$, \\ Cecília Amélia Fazzio Escanhoela ${ }^{2,5}$, Sandra Cecília Botelho Costa ${ }^{3,4}$, Luiz Sérgio Leonardi, ${ }^{1,2}$
}

\begin{abstract}
RESUMO
Desde que o primeiro caso de sarcoma de Kaposi, após transplante renal, foi descrito em 1969, houve um aumento considerável no número de transplantes de órgãos sólidos. 0 objetivo deste trabal ho foi relatar um caso de Sarcoma de K aposi observado após o transplante de fígado. Um paciente masculino, portador de cirrose hepática pelo vírus C, Child B, foi submetido a transplante hepático em fevereiro de 2002. Evoluiu bem no pós-operatório, recebendo alta hospitalar no vigésimo dia após a intervenção cirúrgica usando tacrolimus $0,1 \mathrm{mg} / \mathrm{kg} / \mathrm{dia}$ e $20 \mathrm{mg}$ de prednisona. A pós dois meses, iniciou quadro de emagrecimento, polifagia, polidipsia e poliúria por diabetes, pelo uso da imunossupressão, com controle glicêmico posterior. A pós o quinto mês, apresentou emagrecimento, febre e diarréia. A presentou culturas e sorologias negativas incluindo a sorologia para imunodeficiência adqui rida (HIV ). A colonoscopiafoi normal. Evoluiu duranteainternação com epigastral gia, sendo submetido a endoscopia digestiva alta em jul ho de 2002, evidenciando lesão compatível com sarcoma de K aposi em fundo, antro e corpo gástrico. M anteve quadro de emagrecimento, mau estado geral, evoluindo a óbito em agosto de 2002, apesar da redução da imunossupressão eausência detectável de outras viroses. A seqüência do DNA-H HV-8 foi demonstrada posteriormente (quatro anos após) em amostra de DNA extraída de sangue periférico coletada na época, utilizando-se o método N-PCR OR F-26. A sobrevida após o acometimento visceral foi muito curta, mesmo com diagnóstico precoce.
\end{abstract}

Desaritores: Transplante de Fígado, Hematêmese, Herpesvírus 8 Humano.

Instituição:

1. Departamento de Cirurgia da Faculdade de Ciências Médicas da Universidade Estadual de Campinas

2. Unidade de Transplante Hepático do Hospital de Clínicas da UNICAMP.

3. Laboratório de Diagnóstico de Doenças Infecciosas por Técnica de Biologia Molecular da Faculdade de Ciências Médicas da Universidade Estadual de Campinas.

4. Departamento de Clínica Médica da Faculdade de Ciências Médicas da Universidade Estadual de Campinas.

5. Departamento de Anatomia Patológica da Faculdade de Ciências Médicas da Universidade Estadual de Campinas.

6. FIOCRUZ - Bahia

Correspondência:

Ilka Boin

Rua Aldo Oliveira Barbosa 184

CEP 13086-030 - Campinas - SP - Brasil

Tel/Fax: 551132562254

E-mail: ilka@fcm.unicamp.br

\section{INTRODUÇÃO}

O sarcoma de Kaposi é uma proliferação multifocal maligna de capilares e de células do tecido conjuntivo perivascular da pele e de órgãos internos, sendo uma neoplasia rara. A presenta incidência elevada nas populações com a síndrome da imunodeficiência adquirida e nos pacientes imunossuprimidos farmacologicamente. Sabe-se que a imunossupressão prolongada aumenta a ocorrência de neoplasia nos receptores de órgãos sólidos. ${ }^{1} 0$ sarcoma de $\mathrm{K}$ aposi representa, em freqüência, $6 \%$ das neoplasias em pacientes transplantados e sua incidência varia de 2 a 3,5\%. ${ }^{1}$ Entretanto, a ocorrência de sarcoma de K aposi nos receptores de transplante de fígado érara. ${ }^{2-13} \mathrm{O}$ agente causal foi identificado como $\mathrm{H}$ er pes Vírus Hominis do tipo 8 (HHV-8 DNA). A inda é incerto se a doença é causada pela reativação viral ou pela ação dos imunossupressores, já que há rel ato de soroconversão após a real ização do transplante de fígado. É relatado também que o acometi mento visceral é mais agressivo. A pesar dos diferentes tratamentos propostos, a resposta terapêutica ainda é ineficaz. ${ }^{3,7}$

0 objetivo deste trabalho foi relatar a primeira ocorrência de sarcoma de Kaposi num paciente submetido a transplante hepático em nosso serviço. 


\section{RELATO DO CASO}

O paciente J.A ., 55 anos, sexo masculino, cor branca, casado, brasileiro com cirrose hepática secundária ao vírus da hepatite $C$, iniciou acompanhamento clínico no A mbulatório de Fígado do Hospital de Clínicas da Universidade Estadual de Campinas em outubro de 1999 e foi incluído em lista de espera em fevereiro de 2001. A presentava sorologias negativas para HIV e hepatite B e imunoglobulina $G$ reagente para Epstein-Barr (EBV) e citomegalovírus (CM V). Foi, então, submetido a transplante hepático ortotópico total em fevereiro de 2002 (fígado de doador falecido) pela técnica de piggy-back, quando se apresentava clinicamente classificado como Child-Pugh B. 0 estudo anatomopatológico do fígado explantado confirmou a cirrose, além do achado de carcinoma hepatocelular precoce (medindo cerca de 0,8 x 0,5 cm), bem diferenciado (grau I de Edmondson e Steiner), em nódulo displásico de alto grau no segmento VI. Fez uso de tacrolimus $0,1 \mathrm{mg} / \mathrm{kg} / \mathrm{dia}$ e prednisona, que foi reduzida de $100 \mathrm{mg}$ até $20 \mathrm{mg}$ no primeiro mês, com retirada gradativa ao final do terceiro mês de pós-operatório. Recebeu alta hospitalar no vigésimo dia e manteve-se eutrófico com nível sangüíneo de tacrolimus (5-12 ng/ml) adequado para imunossupressão até o quinto mês de pós-operatório, quando iniciou quadro de diarréia (7-10 evacuações/dia), caracterizada clinicamente como uma diarréia volumosa, líquida, sem sangue ou muco nas fezes, acompanhada de inapetência, adinamia e emagrecimento, necessitando de internação para controle do equilíbrio hidro-eletrolítico. 0 paciente não apresentava qual quer tipo de lesão cutânea na ocasião eas sorologias para 0 vírus HIV e antigenemia e PCR para CM V eram negativas. A pesquisa e cultura de BA A R também foram negativas. $A$ dosagem de alfa-fetoproteína foi de 0,93. O s exames de função hepática mostraram alanina aminotransferase de $28 \mathrm{UI} / \mathrm{I}$, aspartato aminotransferase de 10 $\mathrm{UI} / \mathrm{l}$, y-glutamil transpeptidase de $95 \mathrm{U} / \mathrm{l}$, fosfatase alcalina de $375 \mathrm{UI} / \mathrm{I}$, desidrogenase láctica de $353 \mathrm{UI} / \mathrm{l}$ e bilirrubina total de $1,7 \mathrm{mg} / \mathrm{dl}$. A ultras-sonografia abdominal mostrou um cisto de 4,9cm em segmento II e a biópsia hepática mostrou rejeição celular aguda leve (RA I=3), com fibrose perivenular leve e dilatação sinusoidal leve. Durante a investigação clínica deste quadro diarréico, o paciente foi submetido a endoscopia digestiva alta que evidenciou lesões avermelhadas, arredondadas eal gumas pouco elevadas em corpo efundo do estômago compatíveis macroscopicamente (figura 1) com sarcoma de K aposi. 0 diagnóstico foi confirmado pela biópsia colhida endoscopicamente, que mostrou a presença de células fusiformes formando cordões ou fascículos em várias direções, com ati pias efiguras de mitose epresença defendas vasculares preenchidas por hemáceas, caracterizando o aspecto angiomatóide(figura 2). A imunossupressão foi reduzida, o pacientenão foi submetido a nenhum outro tratamento adjuvante específico para a neoplasia eevoluiu paraóbito um mês após o diagnóstico por hemorragia digestiva alta. A pós quatro anos, conseguimos detectar seqüências de DNA-H HV-8 em duas amostras de DNA extraídas de sangue periférico coletadas em maio de 2002, utilizando-se o método N ested PCR ORF 26. A s amostras coletadas em março foram negativas.

\section{DISCUSSÃO}

O sarcoma deK aposi é uma proliferação multifocal maligna de capilares e de células do tecido conjuntivo perivascular da pele e de órgãos internos, sendo uma neoplasia rara. A presenta incidência elevada nas populações com a síndrome da imunodeficiência adquirida enos pacientes imunossuprimidos. ${ }^{1} \mathrm{~A}$ pesar da freqüência de até 3,5\% entre os pacientes com transplante de órgãos sól idos, eleéraro nos receptores detransplante defígado, sendo relatada uma incidência decerca de dois casos para cada

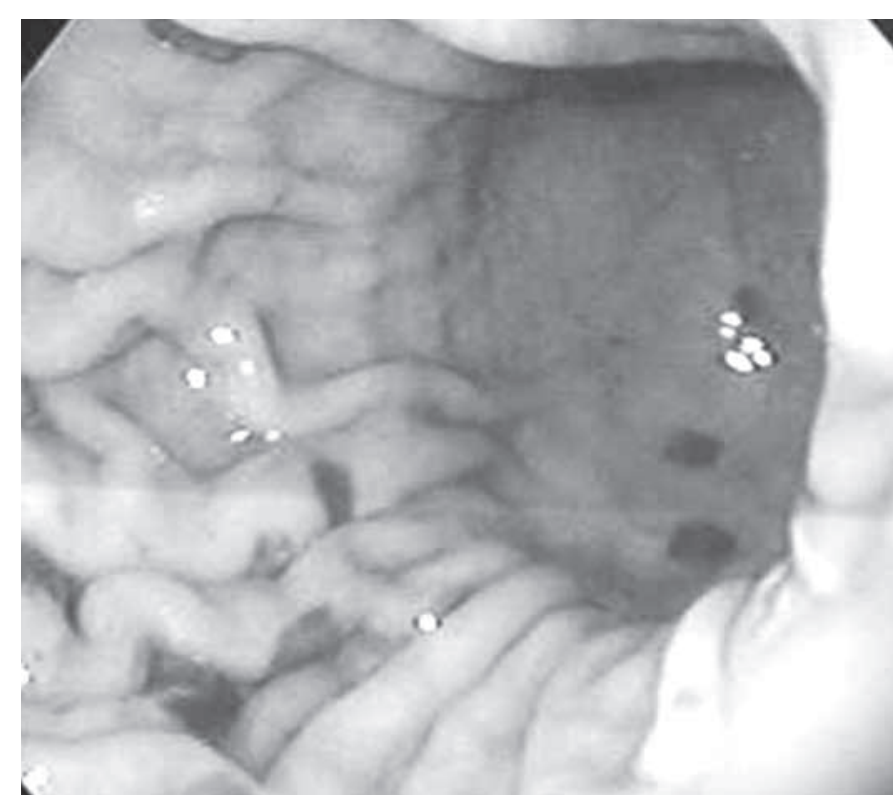

Figura 1 - Aspectos da endoscopia digestiva alta realizada em paciente submetido a transplante de fígado, que evidenciou lesões avermelhadas, arredondadas e algumas pouco elevadas em corpo e fundo do estômago compatíveis, macroscopicamente, com sarcoma de Kaposi

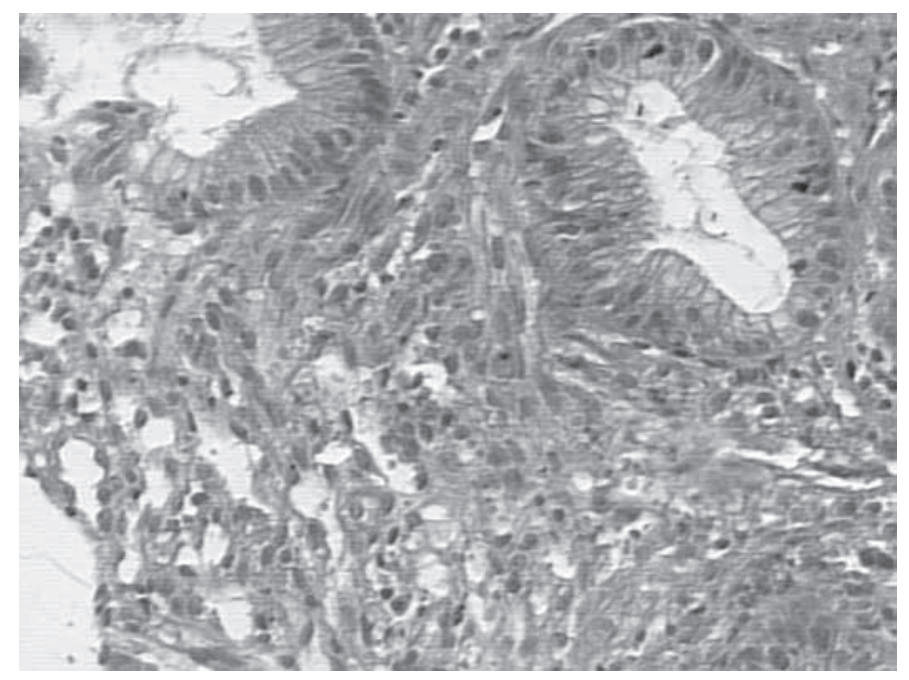

Figura 2 - Biópsia de estômago Sarcoma de Kaposi em paciente submetido a transplante de fígado: presença de células fusiformes formando cordões em várias direções, com atipias e figuras de mitose e presença de fendas vasculares preenchidas por hemáceas, caracterizando 0 aspecto angiomatóide. HE AO X 400

1000 transplantes realizados. ${ }^{2-13}$ Relatamos aqui um caso de paciente submetido ao transplante de fígado, cuja sintomatologia foi observada precocemente. Isto mostrou uma prevalência em nosso serviço de um caso em 330 transplantes real izados, ou seja, 0,3\%.

0 agente causal foi identificado como Herpes Vírus Hominis do tipo 8 (HHV-8 DNA). A inda é incerto se a doença é causada pela reativação viral $^{10}$ devido à ação dos imunossupressores, à infecção primária após o transplante ou se a mesma pode ser potencializada pelo uso da imunossupressão. Há relato de soroconversão após a realização do transplante de fígado. ${ }^{10}$ É relatado também que o acometimento visceral émais agressivo. A pesar dos diferentes tratamentos propostos, a resposta 
terapêutica ainda é ineficaz. ${ }^{10} \mathrm{Em}$ nosso caso, conseguimos efetuar 0 estudo para detecção da seqüência do HHV-8 DN A quatro anos após a realização do transplante. A soroprevalência entre os doadores defígado é desconhecida em nosso meio. A soroprevalência no Brasil varia de acordo com a região analisada. No sudoeste brasileiro varia de 2,4 a $7,4 \%$, conforme estudo realizado entre doadores de sangue, crianças sadias, adolescentes e adultos de algumas cidades de São Paulo.14 Em 2004, autores relataram que a prevalência de HHV-8-DNA, tanto para receptores, como para doadores de fígado, foi de 2,5\%. ${ }^{11}$

A pesar de infecções virais terem sido relacionadas como fatores derisco para o aparecimento do sarcoma deK aposi, observa-se uma prevalência baixa (2/1000) desta neoplasia entre os transplantados de fígado. ${ }^{2-5,7,8,10,11,15}$ Nestes estudos há relatos de soroconversão ocorridas em receptores que receberam enxerto de pacientes infectados com H HV-8.

A imunossupressão também tem sido considerada em alguns relatos como fator derisco, seja por uso de ciclosporina ou pel o uso de tacrolimus, mas não há consenso sobre a qual delas seria imputado maior risco., 7,8,10,12 0 tratamento proposto para esses casos éa redução daimunossupressão e terapia adjuvante com quimi oterapia, radioterapia ou interferon. 1,5,10,11,13 Em nosso caso, suspendemos a imunossupressão e o estado geral do paciente não permitiu nenhuma outra opção terapêutica.

M esmo tendo sido precocemente diagnosticado, a imunossupressão reduzida não se mostrou eficiente para evitar o óbito. Talvez estudos multicêntricos sejam capazes de detectar os fatores de risco relacionados ao transplante de fígado e reduzir a prevalência e/ou melhorar o tratamento deste tipo de tumor.

\section{CONCLUSÃO}

0 caso relatado foi o primeiro ocorrido em nosso serviço. Esperamse melhores alternativas terapêuticas para estes casos, assim como a diminuição na sua incidência, com a melhora progressiva dos imunossupressores.

\section{ABSTRACT}

Since 1969, when the K aposi's sarcoma case was first described in a patient submitted to renal transplantation, there was an increase of such cases in other solid-organ transplant recipients. In our unit, the prevalence of the K aposi's sarcoma in renal transplantations was 3 out of 1000. The aim of this study was to report one K aposi's sarcoma case which appeared in a liver transplantation recipient. A man underwent orthotopic liver transplantation due to hepatitis C virus cirrhosis in February, 2002. Postsurgery status was very good, and the patient was discharged 20 days after OLT. The immunosuppressant protocol consisted to tacrolimus $0.1 \mathrm{mg} / \mathrm{kg} / \mathrm{day}$ and prednisone tapering from $100 \mathrm{mg}$ to $20 \mathrm{mg}$. A fter two months, he showed weakness, polyphagia, polydipsia and polyuria, being diagnosed diabetes after the use of immunosuppressant drugs. The patient presented an improvement; however, afterwards the corticoids were withdrawn, and after the 5th month, he showed weight loss, fever, adynamia and diarrhea. Colonoscopy was normal, viral serology to HIV was negative. Liver function tests were normal. He was re-admitted in the hospital with epigastralgia, and the upper digestive endoscopy showed lesions compatible with $\mathrm{KS}$ in the stomach. Despite a reduction in the immunosuppressant drugs, the patient's clinical conditions deteriorated and he died. Despite the early diagnosis, the visceral involvement was very aggressive. Serological and molecular H H V-8 detection (N-PCR -OR F 26) was prior to the diagnosis of visceral sarcoma, but this was achieved only four years late.

Keywords: Liver Transplantation, Hematemesis, Herpesvírus 8, Human.

\section{REFERÊNCIAS}

1. Cury RA, Barros MF, Pessoa MG et al. An uncommon case of Kaposi’s sarcoma following liver transplantation. Hepatology. 1999;30(4):2009 Part 2 Suppl S.

2. Andreoni M, Goletti D, Pezzotti P, Pozzetto A, Monini P, Sarmati L, et al. Prevalence, incidence and correlates of HHV-8/KSHV infection and Kaposi's sarcoma in renal and liver transplant recipients. J Infect. 2001;43(3);195-9.

3. Goldman DE, Vierling JM, Cambron MG et al. Kaposi's sarcoma following orthotopic liver transplantation. Hepatology. 1997;(4):872 Part 2 Suppl S.

4. Hertzler G, Gordon SM, Piratzky J et al. Case report: fulminant Kaposi’s sarcoma after orthotopic liver transplantation. Am J Med Sci. 1995;(5):278-81.

5. Halmos O, Intierri P, Galligioni A et al. Two cases of Kaposi’s sarcoma in renal and liver transplant recipients treated with interferon. Clin Transplant. 1996;10(4):374-8.

6. Iscovich J, Boffeta P, Franceschi S et al. Classic Kaposi sarcoma. Epidemiology and risk factors. Cancer. 2000;88(3):500-17.

7. Rezeig MA, Fashir BM, Hainar B et al. Kaposi’s sarcoma in liver transplant recipients on FK-506. Two case reports. Transplantation. 1997;63(10):1520-1.

8. Vial T, Descotes J. Immunosuppressive drugs and cancer. Toxicology. 2003;185(3):229-40.
9. Vitaux J, Roseau G. Endoscopic aspect of Kaposi sarcomas of the stomach. Presse Med. 1999;2 (27):1495.

10. Aseni P, Vertemati M, Arcieri K, Bonacina E, Camozzi M, Osio C, et al. Kaposi’s sarcoma in liver transplant recipients morphological and clinical description. Liver Transpl. 2001;7(9):816-23.

11. Marcelin AG, Roque-Afonso AM, Hurtova M, Dupin N, Tulliez M, Sebagh M et al. Fatal disseminated Kaposi's sarcoma following human herpes vírus 8 prymary infections in liver-transplant recipients. Liver Transpl. 2004,10(2):295-300.

12. Vallejo GH, Romero CJ, de Vicente JC. Incidence and risk factors for câncer after liver transplantation. Crit Rev Oncol Hematol. 2005;56:87-99.

13. Verucchi G, Calza L, Trevisani F, Zambruni A, Tadolini M, Giuliani R et al. Human herpesvirus-8 related Kaposi's sarcoma after liver transplantation successfully treated with cidofovir and liposomal daunorubicin. Transpl Infec Dis . 2005;7:34-7.

14. Souza VAUF, Sumita LM, Freire W, Sato HK, Grandi JL, PierrottibLC et al. Prevalence of antibodies to human herpesvirus-8 in populations with and without risk for infection in Sao Paulo State. Braz J Med Biol Res. 2004;37:123-7.

15. Garcia-Sesma A, Jimenéz C, Loinaz C, Meneu JC, Colina F, Marqués E et al. Kaposi’s visceral sarcoma in liver transplant recipients. Transplant Proc. 2003;35:1898-9 


\section{NORMAS DE PUBLICAÇÃO}

O JBT - Jornal Brasileiro de Transplantes, ISSN 1678-3387, órgão oficial da A BTO - A ssociação B rasileira de Transplante de Ó rgãos, destina-seà publicação de artigos da área de transplante e especialidades afins, escritos em português, inglês ou espanhol.

Os manuscritos submetidos à R evista, que atenderem às "Instruções aos A utores" e estiverem de acordo com a política Editorial da Revista, após aprovação pelo Consel ho Editorial, serão encaminhados para análise e avaliação de dois revisores, sendo 0 anonimato garantido em todo o processo de julgamento. Os comentários serão devolvidos aos autores para as modificações no texto ou justificativas de sua conservação. Somente após aprovação final dos editores e revisores, os trabal hos serão encaminhados para publicação. Serão aceitos A rtigos O riginais, A rtigos de R evisão, A presentação de Casos Clínicos, Cartas ao Editor, Ciências B ásicas A plicadas aos Transplantes, 0 pinião Técnica, Prós e Contras, I magem em Transplante e Literatura M édica e Transplantes.

\section{ARTIGOS ORIGINAIS}

São trabal hos destinados à divulgação de resultados da pesquisa científica. Devem ser originais e inéditos. Sua estrutura deverá conter os seguintes itens: Resumo, Introdução, M étodos, R esultados, Discussão, Conclusão e R eferências e A bstract. Devem ter, no máximo, 35 referências.

\section{ARTIGOS DE REVISÃO}

Constituem da avaliação crítica e sistemática da literatura sobre um assunto específico, podendo ser: Revisão A cadêmica, Revisão de Casos, Revisões Sistemáticas, etc. 0 texto deve esclarecer os procedimentos adotados na revisão, a delimitação e os limites do tema, apresentar conclusões e ou recomendações e ter, no máximo, 50 referências.

\section{APRESENTAC̣ÃO DE CASOS CLÍNICOS}

Relata casos de uma determinada doença, descrevendo seus aspectos, história, condutas, etc... incluindo breve revisão da literatura, com 15 referências, no máximo.

\section{CARTAS AO EDITOR}

Tem por objetivo discutir trabal hos publicados na revista ou relatar pesquisas originais em andamento. Devem ter, no máximo, três laudas e cinco referências.

\section{CIÊNCIAS BÁSICAS APLICADAS AOS TRANSPLANTES}

A rtigos de revisão sobre temas de ciência básica, cujo conhecimento tem repercussão clínica relevante para Transplantes. Devem ter, no máximo, dez laudas e 15 referências e serão feitas apenas a convite do J BT.

\section{OPINIÃO TÉCNICA}

Destina-se a publicar uma resposta a uma pergunta de cunho prático através de opinião de um especialista (Quem? Quando? Como? Onde? Por quê?). Devem ter, no máximo, seis laudas e apresentarem três referências.

\section{PRÓS E CONTRAS}

Frente a uma questão, dois autores serão escol hidos pela editoria do J BT, para discutirem os aspectos positivos e os negativos de um assunto controvertido. São dois autores, um escrevendo a favor e o outro contra uma determinada proposição. Cada autor deve escrever no máximo três laudas e cinco referências.

\section{IMAGEM EM TRANSPLANTE}

U ma imagem relacionada a Transplante, patognomônica, típica, deUS, RX, CT, R N M , foto de cirurgia, microscopia, sinal clínico, etc., seguida de um texto curto, explicativo, de, no máximo, 15 linhas e três referências.

\section{LITERATURA MÉDICA E TRANSPLANTES}

Um artigo original de qualquer área médica, incluindo transplantes, que seja importante para o conhecimento do médico transplantador, poderá ser revisado, e o resumo do trabal ho original será publicado, seguido de um pequeno resumo comentado ressaltando sua importância. 0 resumo deve ter até duas laudas e apresentar a referência completa do trabal ho. A utores serão convidados para esse tipo de publicação, mas poderão ser considerados para publicação no J BT trabaIhos enviados sem convites quando considerados relevantes pelos editores.

A s normas que se seguem, devem ser obedecidas para todos os tipos de trabal hos e foram baseadas no formato proposto pelo I nternational Committee of M edical J ournal Editors e publicado no artigo: Uniform requirements for manuscripts submitted to biomedical journals. A nn Intern M ed 1997;126;36-47, e atual izado em outubro de 2001. Disponível no endereço eletrônico: http://www.icmje.org

O bs: : Uma lauda $=2.800$ toques (incluindo espaços), formato Word for Windows, A4, cp.12, espaço 1,5.

\section{NORMAS PARA ELABORACÃO DO MANUSCRITO}

\section{Requisitos técnicos}

a) 0 trabal ho deverá ser digitado em espaço duplo, fonte A rial tamanho 12 , margem de 2,5 cm de cada lado, com páginas numeradas em algarismos arábicos, iniciando cada seção em uma nova página, na seqüência: página de título, resumo e descritores, texto, agradecimentos, referências, tabelas e legendas. Se impresso, deverão ser enviadas duas cópias, em papel tamanho ISO A 4 (210×297mm), mais uma cópia digital (disquete ou CD-ROM )

b) Permissão à A BTO para reprodução do material;

c) A provação de um Comitêde Ética da Instituição onde foi realizado o trabal ho, quando referente a trabal hos de pesquisa envolvendo seres humanos.

d) Declaração que o manuscrito não foi submetido a outro periódico, contendo assinatura de todos os autores.

e) Conflitos de interesse de cada autor.

A pós as correções sugeridas pelos revisores, a forma definitiva do trabal ho deverá ser encaminhada por e-mail ou, se impresso, em duas vias, com cópia em disquete $3^{1 / 2}$ ou em CD-ROM . Os originais não serão devolvidos.

Somente o J BT-J ornal B rasileiro de Transplantes poderá autorizar a reprodução em outro periódico, dos artigos nele contidos.

O Corpo E ditorial poderá aceitar a publicação de trabal hos de outra natureza ou escritos em outra língua.

\section{PREPARO DO MANUSCRITO}

\section{A página inicial deve conter:}

a) Título do artigo, em português (ou espanhol) e inglês, sem abreviaturas; que deverá ser conciso, porém informativo;

b) Nome completo de cada autor, com o seu grau acadêmico e afiliação institucional;

c) Nome do departamento e instituição aos quais o trabal ho deve ser atribuído;

d) Nome, endereço completo, fax e e-mail do autor responsável e a quem deve ser encaminhada correspondência;

e) fontes de auxílio à pesquisa, se houver. 